\title{
Stochastic Risk Analysis Of Budgeted Financial Statements
}

Dennis F. Togo, (E-mail: togo@unm.edu), University of New Mexico

\begin{abstract}
Stochastic modeling of financial statements facilitates risk analysis by explicitly introducing uncertainty for key input variables. When input variables are modeled as probability distributions, then Monte Carlo simulation can be performed for the budgeted financial statements. Critical outputs within the financial statements can be displayed with cumulative graphs that show a range of outcomes with its likelihood of occurrence. Stochastic modeling techniques are superior to scenario analysis in assessing risk and are another innovative use of technology in support of managerial decision-making. Students for a cost/managerial accounting course reported a better understanding of risk analysis for accounting relationships, and a greater interest in modeling uncertainty in other financial relationships.
\end{abstract}

\section{INTRODUCTION}

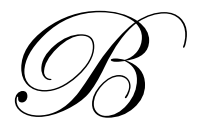

usiness students that have meticulously prepared a master budget for a cost/managerial accounting course often have difficulty understanding why actual financial results for a company do not turn out as budgeted. An explanation often not well understood by students is that financial budgets are prepared with inputs having expected values; while actual financial results are determined by numbers that are usually not equal to but fairly close to the original expected values. Even after a discussion and demonstration of most likely, best-, and worst-case scenarios, some students still have difficulty accepting the variability within a modeled relationship.

A risk analysis case demonstrates the benefits of stochastic modeling over scenario analysis by examining the impact of key input variables on critical outputs for a set of financial statements. With the aid of a spreadsheet add-in, probability distributions for input variables are used to perform Monte Carlo simulation. The simulation results are compared to common scenario analysis techniques to highlight the benefits of stochastic modeling.

\section{RISK ANALYSIS: SCENARIOS VERSUS SIMULATION}

A goal of scenario analysis is to formulate a skeletal distribution of critical output variables by changing key input variables. However, scenario analysis has drawbacks when identifying expected combinations of input variables and the weighting of the selected values for the inputs. Recognizing scenarios for a complex model is challenging due to the many input variables and their interrelationships. Furthermore, without a weighting (probability) assigned to the selected values for an input variable, the model's outcomes for the most likely, best-, and worst-case scenarios are difficult to validate. As a consequence, scenario analysis may generate a skeletal distribution for a critical output variable that is misleading.

A deterministic model can be easily converted into a stochastic model by having input variables represented with probability distributions instead of expected values. The input probability distributions have an explicit range and weighting for each value. Monte Carlo simulation selects input values from their probability distributions and computes the output values of the model. After repeating this process many times, the results for the output variables can be displayed with a useful cumulative probability graph that identifies its mean, minimum and maximum values, and percentiles for specific values of outcomes. The following case will perform scenario analysis and then simulation with the spreadsheet add-in @ RISK to demonstrate the benefits of a stochastic approach to risk analysis. 


\section{TIANA COMPANY: AN EXAMPLE OF STOCHASTIC RISK ANALYSIS}

\section{Overview}

Tiana Company retails fashion accessories for pre-teen girls. In this growing high-risk market, it is important to carry the latest fad being advertised on successful TV programs. The cost of merchandise also fluctuates with the success of the TV program. The budgeted financial statements of Tiana Company consist of an income statement, a balance sheet, and a statement of cash flows. The set of three statements relate many input variables (assumptions) in its completion; hence, they provide a useful vehicle to assess the impact of key input variables on critical financial outcomes.

Students first build the budgeted financial statements for Tiana Company from expected values of key input assumptions. Then they are to perform scenario analysis for the critical outputs operating income and cash borrowings. Finally, students perform Monte Carlo simulation for the same output variables by introducing probability distributions for key input variables.

\section{Procedure}

Students access a spreadsheet template that lists input variables (Exhibit 1 - Panel A), and account names, column headings, and beginning balances of the budgeted financial statements (Exhibit 2). On their own copy of the spreadsheet template, the students complete the budgeted financial statements by entering formulas that refer to the input assumptions. The students receive a hard copy of the completed budgeted financial statements (Exhibit 2) to help their model building. Furthermore, they can debug their model by accessing a check-figure spreadsheet which allows for changes to input assumptions while hiding formulas for the financial statements.

\section{Scenario Risk Analysis}

The budgeted financial statements of Exhibit 2 indicate $\$ 2,000$ Operating income and $\$ 1,400$ Borrowings for the year. Scenario analysis for these two critical output variables are performed by changing four key input variables - Selling price - \$440, Qtr4 unit sales - 140, Inventory cost per unit - \$360, and Sales collected current qtr - $\$ 60 \%$. Four equally spaced data points $\mathrm{A}, \mathrm{B}, \mathrm{D}$, and $\mathrm{E}$ around the expected value $\mathrm{C}$ are used to generate the scenario analysis data tables (Panel As) for operating income (Exhibit 3) and borrowings (Exhibit 4). For example, Selling price has a $\mathrm{C}$ base case price of $\$ 440$, A price of $\$ 420$, B price of $\$ 430$, D price of $\$ 450$, and E price of $\$ 460$, with related Operating income of $\$ 2,000,-\$ 7,000,-\$ 2,500, \$ 6,500$, and $\$ 11,000$, respectively.

The scenario analysis results of Operating income and Borrowings for the four data points are graphed as lines in Panel A of Exhibits 3 and 4. A positive/negative slope for an input variable indicates a favorable/unfavorable impact on the output variable. Furthermore, the slope of the line indicates the output variable's sensitivity to changes in the input variable. The graphical results in Exhibit 3 for Operating income show the expected strong positive sensitivity to selling price but a strong negative sensitivity to inventory cost. The graphical results in Exhibit 4 for Borrowings understandably show a strong negative sensitivity to selling price but a strong positive sensitivity to inventory cost. However, with only four more equally-spaced data points and no weights assigned to them, the effects for selling price and inventory cost on the outcome variables operating income and borrowings were examined further with stochastic analysis.

\section{Stochastic Modeling}

Simulation modeling provides for the underlying distribution of input variables instead of their expected value to be used in computing output variables. The critical input variables selling price and inventory cost of Tiana Company could have variability caused by several factors: conflicting views of competition, "fad" popularity among pre-teen shoppers, and uncertain availability of the merchandiser inventory. 
Distributions for selling price and inventory cost (Exhibit 1 - Panel B) are used to illustrate simulation modeling with the spreadsheet add-in (@RISK ( $\$ 40$ student version, Duxbury publishers). The means of the probability distributions are also the expected values for $\$ 440$ selling price and the $\$ 360$ inventory cost.

- $\quad$ Selling price $=$ RiskHistogrm $(420,460,\{0.3,0.1,0.3\})$

- $\quad$ Inventory cost $=\operatorname{Triang}(350,355,375)$

The students enter the selling price distribution as a histogram with a minimum value of $\$ 420$ and a maximum value of $\$ 460$, with the range divided into three equal-length classes with probability weights of $.3, .1$ and .3. The inventory cost is a triangular distribution with a minimum value of $\$ 350$, a most likely value of $\$ 355$ and a maximum value of $\$ 375$.

\section{Stochastic Risk Analysis}

The students enter a simulation setting of $\mathrm{n}=10,000$ iterations, and select as outputs operating income and cash borrowings. Upon completing the simulation, the targeted outputs are chosen to be graphically presented, as depicted in panel B of Exhibits 3 and 4, respectively. The cumulative output graphs present to students a range of outcomes with related probabilistic data not available with scenario analysis.

The simulation results for operating income show a $\$ 2,000$ mean for a bimodal distribution, a $42.84 \%$ likelihood of not having a positive value, and a $22.39 \%$ likelihood of having at least an $\$ 8,000$ operating income. The graphical results for cash borrowings show a distribution having a simulation mean of $\$ 2,400$, a $49.42 \%\{100 \%$ $(30.46 \%+20.12 \%)\}$ likelihood of borrowing up to $\$ 1,400$ (expected mean), and $79.88 \%\{100 \%-20.12 \%\}$ likelihood of borrowing up to $\$ 5,000$. Students quickly recognize that cash borrowings should not be limited to the $\$ 1,400$ expected value; instead, they may elect to cover $80 \%$ of the outcomes for cash borrowings with a $\$ 5,000$ line of credit.

\section{STUDENT FEEDBACK}

The added information from stochastic modeling of the financial statements allows students to better consider the risk associated with managerial decisions. Students quickly identify other managerial decisions that would benefit from simulation modeling such as capital budgeting, economic order quantity, sales forecasts and costvolume-profit analysis. Files for the Tiana Company Case are available upon request from the author.

In completing this risk analysis case, students also improve their spreadsheet skills and understanding of financial relationships. For 41 business students completing a post-survey of the case (scale of 1 poor to 5 excellent), spreadsheet skills improved from 2.8 to 4.0 . The students favorably responded that the case facilitated the learning of relationships among financial statements with a score of 4.7 , and that the modeling case rated overall at 4.6.

\section{SUMMARY}

This exercise demonstrates to business students why actual results will differ from budgeted amounts for financial statements prepared using only expected values. The benefits of performing stochastic modeling and Monte Carlo simulation over scenario analysis were illustrated with key financial outputs of financial statements. Instructors should adopt the stochastic modeling of financial models and the use of spreadsheet simulation to present an interesting and realistic method of risk analysis. 
Exhibit 1: Input Variables and Probability Distributions

Panel A: Input Variable and Expected Value Assumptions

Input Variable

Selling price

Qtr1 unit sales

Qtr2 unit sales

Qtr3 unit sales

Qtr4 unit sales

Next year Qtr1 unit sales

Minimum cash balance
Input Variable

Sales collected current qtr

Inventory cost per unit

Ending inventory needed

Inventory paid current qtr

S\&A variable expense

S\&A fixed expense

Annual interest rate

Expected Value
$60 \%$
$\$ 360$
$25 \%$
$40 \%$
$\$ 40$
$\$ 4,000$
$12 \%$

\section{Panel B: Probability Distributions of Key Inputs}

Graphs of Probability Distributions

Selling Price

RiskHistogrm(420,460, $\{0.3,0.1,0.3\})$

Inventory Cost

RiskTriang $(350,355,375)$

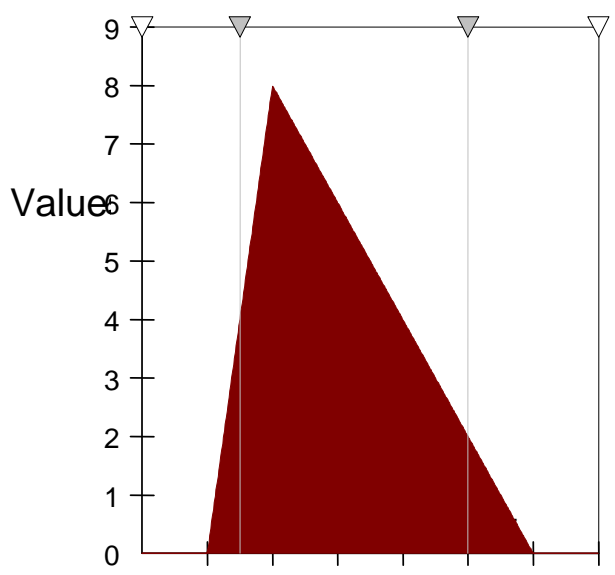

\begin{tabular}{|l|l|l|}
\hline $5.0 \%$ & $90.0 \%$ & $5.0 \%$ \\
\hline 352.5000 & 370.0000
\end{tabular}




\section{Exhibit 2: Budgeted Financial Statements}

\section{Income Statement}

Sales

Beginning inventory

Purchases of inventory

(Ending inventory)

Cost of goods sold

Gross profit

S\&A expense

Operating income (loss)

Interest expense

Net income (loss)

\section{Cash Flow Statement}

Beginning cash

Receipts - prior sales

Receipts - current sales

Cash available

Payment - prior purchases

Payment - current purchases

Cash paid - S\&A expense

Minimum cash balance

Cash needs

Excess (deficiency)

Financing:

Borrowings

(Repayments)

(Interest paid)

Net financing

Ending cash
Qtr

$\underline{39,600}$

8,100

33,300

$(9,000)$

$\underline{32,400}$

7,200

$\underline{7,600}$

$\frac{7,600}{(400)}$

$\frac{10}{(410)}$

Qtr1

8,000

21,120

23,760

$\underline{52,880}$

24,300

13,320

7,600

$\underline{8,000}$

$\underline{53,220}$

(340)

340

$\begin{array}{r}0 \\ 0 \\ \hline 340 \\ \hline 8.000\end{array}$

Beginning

Balance

8,000

Cash

Accounts receivables

Merchandise inventory

Net fixed assets

Total Assets

Accounts payable

Note payable

Interest payable

Paid-in-capital

Retained earnings

Total Liab. and SE

21,120

8,100

$\underline{15,625}$

$\underline{52,845}$

24,300

25,000

$\underline{3,545}$

$\underline{52,845}$

\begin{tabular}{|c|c|c|c|}
\hline $\begin{array}{r}\text { Qtr2 } \\
44,000 \\
\end{array}$ & $\begin{array}{r}\text { Qtr3 } \\
52,800 \\
\end{array}$ & $\begin{array}{r}\text { Qtr4 } \\
61,600 \\
\end{array}$ & $\begin{array}{r}\text { Year } \\
198,000 \\
\end{array}$ \\
\hline 9,000 & $\overline{10,800}$ & $\overline{12,600}$ & 8,100 \\
\hline 37,800 & 45,000 & 46,350 & 162,450 \\
\hline$(10,800)$ & $(12,600)$ & $(8,550)$ & $(8,550)$ \\
\hline 36,000 & 43,200 & 50,400 & 162,000 \\
\hline 8,000 & 9,600 & 11,200 & 36,000 \\
\hline$\underline{8,000}$ & $\underline{8,800}$ & $\underline{9,600}$ & $\underline{34,000}$ \\
\hline 0 & 800 & 1,600 & 2,000 \\
\hline 36 & 42 & 42 & 130 \\
\hline$(36)$ & 758 & 1,558 & 1,870 \\
\hline Qtr2 & Qtr3 & Qtr4 & Year \\
\hline 8,000 & 8,000 & 8,000 & 8,000 \\
\hline 15,840 & 17,600 & 21,120 & 75,680 \\
\hline$\underline{26,400}$ & $\underline{31,680}$ & $\underline{36,960}$ & $\underline{118,800}$ \\
\hline$\underline{50,240}$ & $\underline{57,280}$ & $\underline{66,080}$ & $\underline{202,480}$ \\
\hline$\overline{19,980}$ & 22,680 & $\overline{27,000}$ & 93,960 \\
\hline 15,120 & 18,000 & 18,540 & 64,980 \\
\hline 8,000 & 8,800 & 9,600 & 34,000 \\
\hline$\underline{8,000}$ & $\underline{8,000}$ & $\underline{8,000}$ & $\underline{8,000}$ \\
\hline$\underline{51,100}$ & $5 \overline{7,480}$ & 63,140 & 200,940 \\
\hline$(860)$ & $(200)$ & $\underline{2,940}$ & $\underline{1,540}$ \\
\hline 860 & 200 & 0 & 1,400 \\
\hline 0 & 0 & $(1,400)$ & $(1,400)$ \\
\hline 0 & $\underline{0}$ & $(130)$ & $(130)$ \\
\hline 860 & 200 & $(1,530)$ & $(130)$ \\
\hline$\underline{8,000}$ & $\underline{8,000}$ & $\underline{9,410}$ & 9,410 \\
\hline
\end{tabular}

\section{Qtr1}

8,000

15,840

9,000

15,625

48,465

19,980

340

10

25,000

$\underline{3,135}$

48,465

$\begin{array}{rrr}\text { Qtr2 } & \text { Qtr3 } & \text { Qtr4 } \\ 8,000 & 8,000 & 9,410 \\ 17,600 & 21,120 & 24,640 \\ 10,800 & 12,600 & 8,550 \\ \underline{15,625} & \underline{15,625} & \underline{15,625} \\ \underline{52,025} & \underline{57,345} & \underline{58,225} \\ 25,313 & 27,563 & 27,844 \\ 1,200 & 1,400 & 0 \\ 46 & 88 & 0 \\ 25,000 & 25,000 & 25,000 \\ \underline{3,099} & \underline{3,857} & \underline{5,415} \\ \underline{52,025} & \underline{57,345} & \underline{58,225}\end{array}$


Exhibit 3: Operating Income Scenario Analysis and Simulation Results

Panel A - Scenario Analysis

\begin{tabular}{|c|c|c|c|c|c|c|c|c|}
\hline Data Point & $\underline{\mathrm{SP}}$ & OI & Qtr4 & OI & $\underline{\operatorname{Inv}}$ & OI & Coll\% & OI \\
\hline A & 420 & $-7,000$ & 120 & 1,200 & 340 & 11,000 & $56 \%$ & 2,000 \\
\hline B & 430 & $-2,500$ & 130 & 1,600 & 350 & 6,500 & $58 \%$ & 2,000 \\
\hline C & 440 & 2,000 & 140 & 2,000 & 360 & 2,000 & $60 \%$ & 2,000 \\
\hline D & 450 & 6,500 & 150 & 2,400 & 370 & $-2,500$ & $62 \%$ & 2,000 \\
\hline $\mathrm{E}$ & 460 & 11,000 & 160 & 2,800 & 380 & $-7,000$ & $64 \%$ & 2,000 \\
\hline
\end{tabular}

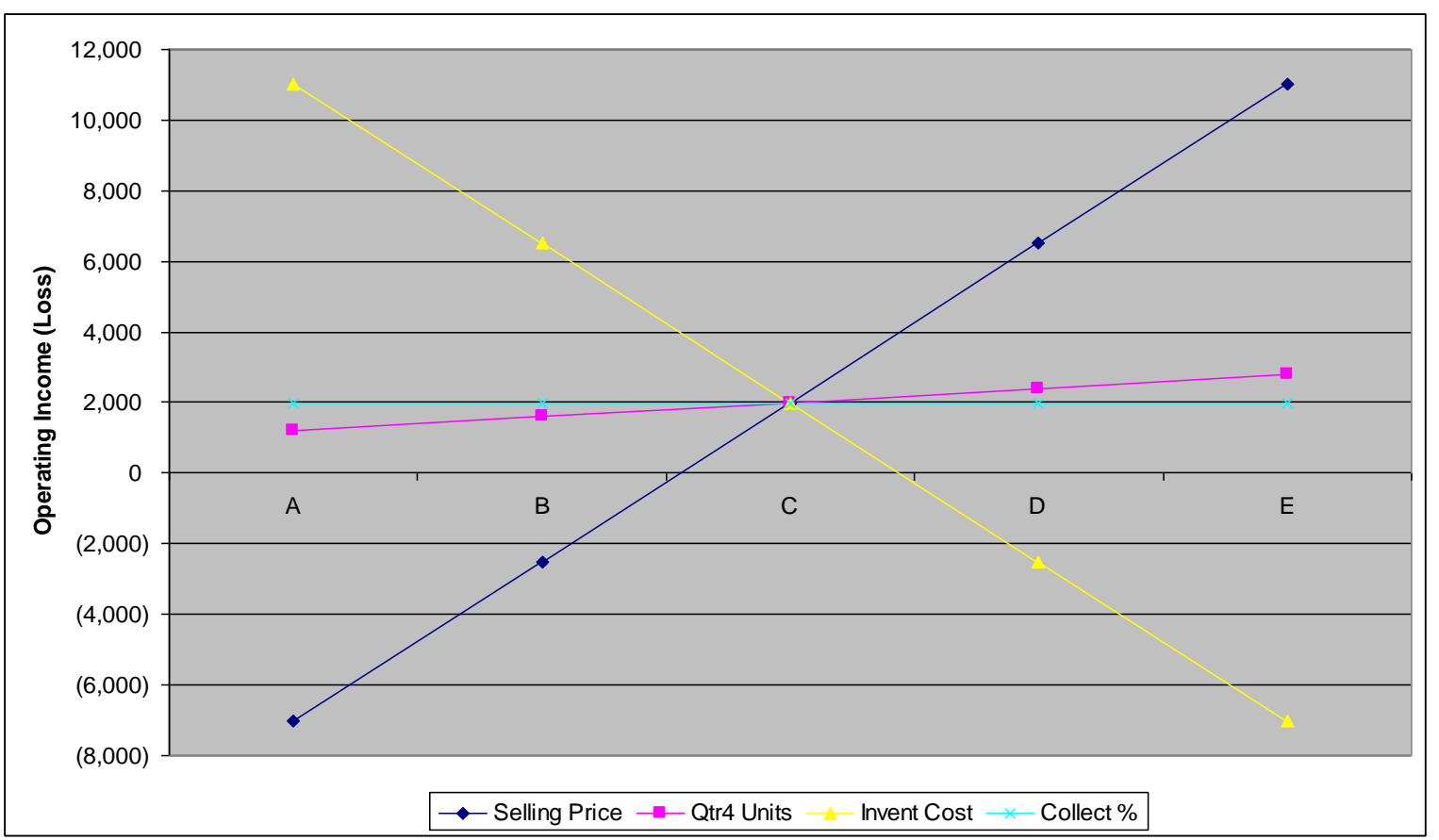

Panel B - Simulation Results

Distribution for Operating income / Year

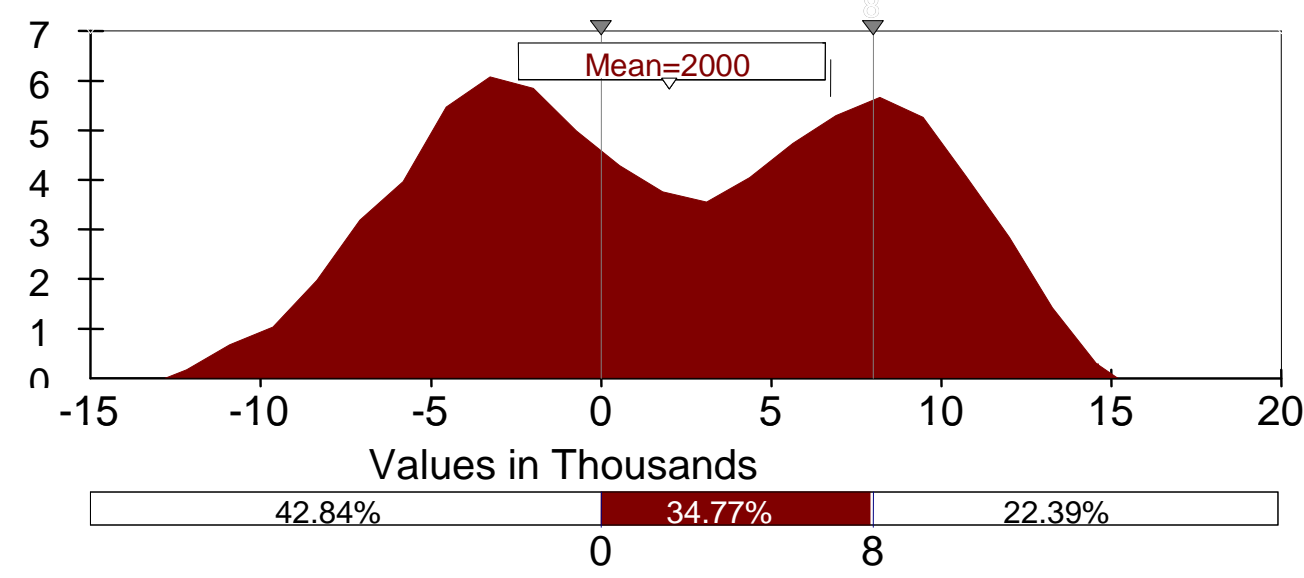


Exhibit 4: Borrowings Scenario Analysis and Simulation Results

Panel A - Scenario Analysis

$\begin{array}{crrrrrrrr}\text { Data Point } & \underline{\text { SP }} & \text { Borrow } & \text { Qtr4 } & \text { Borrow } & \underline{\text { Inv }} & \text { Borrow } & \text { Coll\% } & \text { Borrow } \\ \text { A } & 420 & 6,640 & 120 & 1,200 & 340 & 0 & 56 \% & 3,512 \\ \text { B } & 430 & 4,020 & 130 & 1,200 & 350 & 0 & 58 \% & 2,456 \\ \text { C } & \mathbf{4 4 0} & \mathbf{1 , 4 0 0} & \mathbf{1 4 0} & \mathbf{1 , 4 0 0} & \mathbf{3 6 0} & \mathbf{1 , 4 0 0} & \mathbf{6 0 \%} & \mathbf{1 , 4 0 0} \\ \text { D } & 450 & 0 & 150 & 1,760 & 370 & 4,100 & 62 \% & 344 \\ \text { E } & 460 & 0 & 160 & 2,120 & 380 & 6,800 & 64 \% & 0\end{array}$

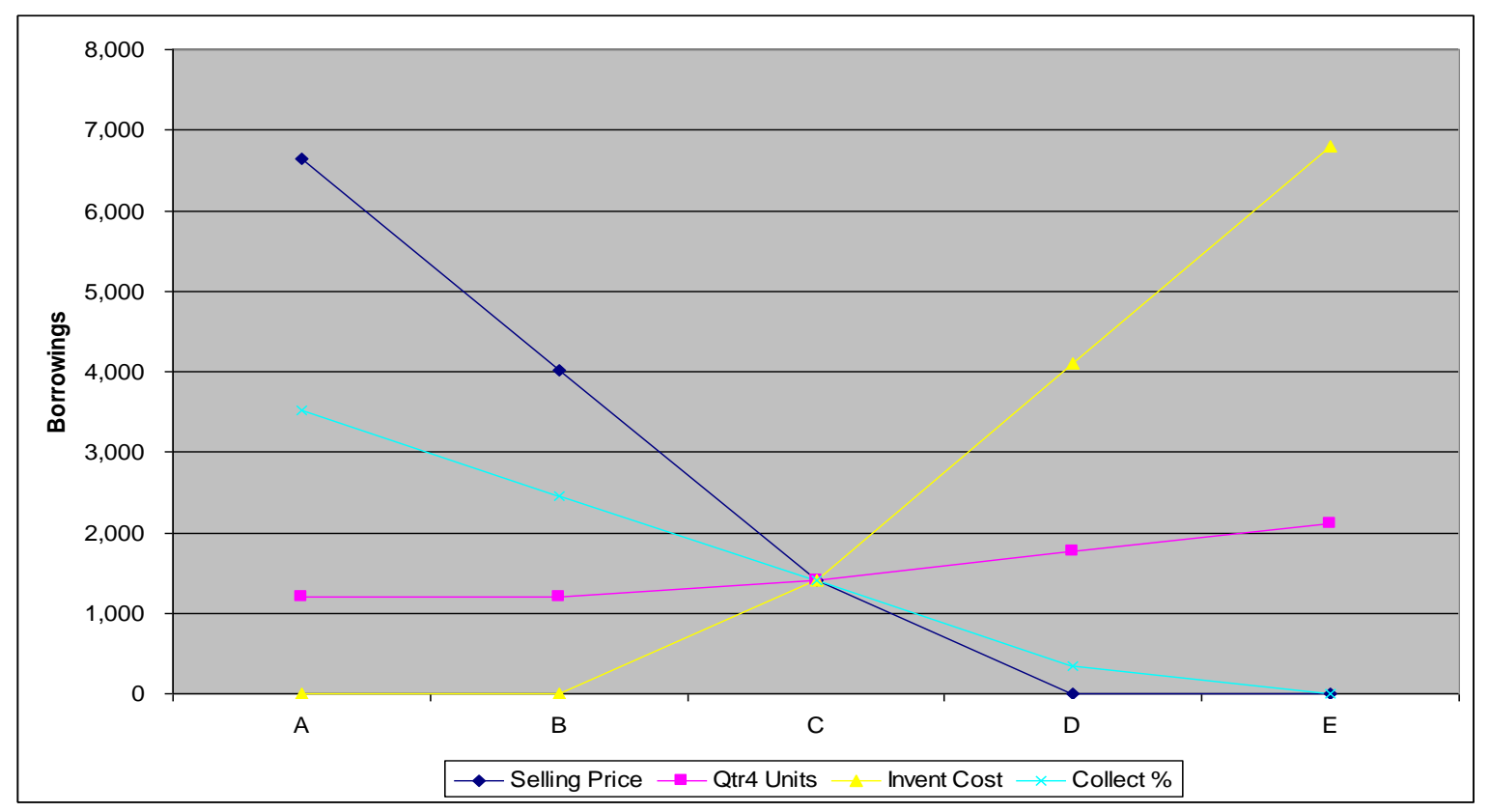

Panel B - Simulation Results

Distribution for Borrowings / Year

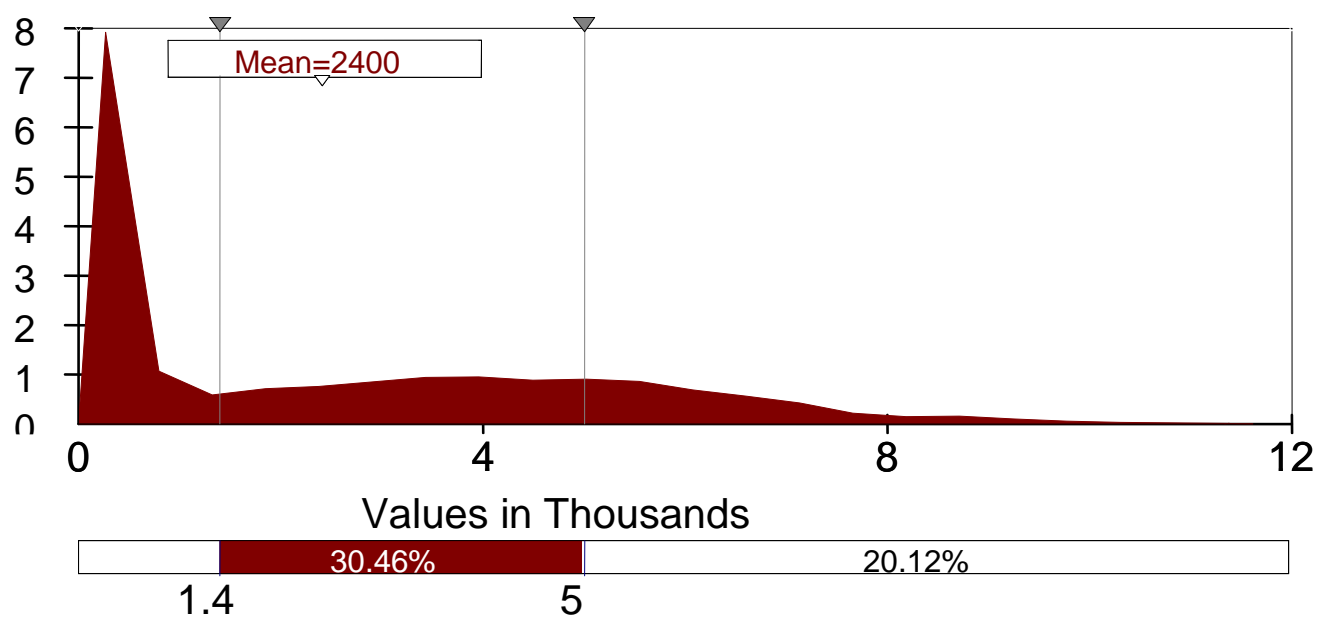




\section{NOTES}

